\title{
ANALISIS KEPUASAN NASABAH ATAS KUALITAS LAYANAN INTERNET BANKING PADA PT BANK RAKYAT INDONESIA (Persero) Tbk. UNIT BANYUMANIK SEMARANG
}

\author{
Wahyu Febriyanti *) \\ Sri Widiyati **)
}

\begin{abstract}
The purpose of this research is to identify how to increase customer satisfaction of Internet Banking Service Quality at PT Bank Rakyat Indonesia (Persero) Tbk. Unit Banyumanik Semarang with five dimensions of service quality which were tangible, reliability, responsiveness, assurance, and emphaty.

Data in this research were obtained from questionnaires which spread to 100 (one hundred) respondents. The data analysis methods are validity test, reliability test, satisfaction index analysis, and satisfaction gap test.

The results from reliability and validity tests showed that items of service quality dimension such as tangible, reliability, responsiveness, assurance, and empathy were valid and reliable. Based on the result of satisfaction index analysis, the weighting average score of Internet Banking quality service is 4,046. That score is between 3,43-4,23 which means satisfied. Based on the result of satisfaction gap test the increase of satisfaction established on the fifteen sub indicators show satisfaction, and three sub indicators show dissatisfaction, then it needs special attention and an improvement from PT Bank Rakyat Indonesia (Persero) Tbk. Unit Banyumanik Semarang for three sub-indicators are not satisfied.
\end{abstract}

Keywords : Customer Satisfaction, Service Quality, Internet Banking.

*) Mahasiswa Tugas Akhir Prodi Keuangan dan Perbankan, Jurusan Akuntansi, Politeknik Negeri Semarang

**) Dosen Jurusan Akuntansi, Politeknik Negeri Semarang

\section{PENDAHULUAN}

\section{Latar Belakang Masalah}

Dalam kegiatan industri modern saat ini, tingkat mobilitas dan kesibukan yang semakin meningkat mengakibatkan banyak orang membutuhkan alat yang bisa dengan cepat dan tepat dalam pemenuhan kebutuhan mereka. Salah satunya adalah sektor industri perbankan. Di era globalisasi, perbankan merupakan bisnis yang mengelola kepercayaan. Hal ini terkait dengan pengolahan data dan informasi tentang perbankan yang akan diberikan kepada nasabah, selain itu keakuratan dan kecepatan aspek keamanan perbankan juga dipertimbangkan. Keberhasilan dalam pengamanan data akan meningkatkan kredibilitas sebagai lembaga kepercayaan masyarakat (agent of trust) dan juga dapat meningkatkan peranan bank sebagai instrument moneter dalam lalu lintas 
pembayaran yang dapat mencegah kerugian yang akan mempengaruhi keuangan bank yang bersangkutan (Hasibuan, 2008:35).

Oleh karena itu dalam dunia perbankan saat ini mengembangkan internet banking yang mempunyai tujuan sebagai fasilitas bagi para nasabah dalam rangka menjalankan kegiatan keuangan bank tersebut. Kemajuan di bidang teknologi ini akan mempermudah nasabah bank bertransaksi di mana pun mereka berada tanpa perlu mengantri panjang untuk melakukan transaksi dengan kecanggihan teknologi yang ada saat ini yaitu dengan bertransaksi melalui internet banking.

Marketing Research Indonesia (MRI) dan Infobank menyajikan data mengenai perkembangan kualitas pelayanan indsutri perbankan kepada nasabah individual melalui Walk in Channelyaitu kantor cabang, Auto Teller Machine(ATM) manapun melalui Electronic Chanel(eChannel), yaitu Phone Banking, SMS Banking, Mobile Banking (m-Banking) dan Internet Banking. MRI melakukan pengukuran kualitas pelayanan perbankan yang bertajuk Bank Service Excellence Monitor (BSEM) dengan misi memacu perbankan agar memberikan pelayanan terbaik kepada nasabah. Posisi Bank Rakyat Indonesia berdasarkan hasil survei MRI dari sisi kualitas pelayanan internet banking sebagaimana digambarkan pada Tabel 1.1 berikut ini:

Tabel 1

Daftar 10 bank Peraih Best Bank Service Excellence Kategori Performa Terbaik Internet Banking Tahun 2016-2017

\begin{tabular}{|c|l|c|c|}
\hline \multirow{2}{*}{ Peringkat } & \multicolumn{2}{|c|}{ Nama Bank } & \multicolumn{2}{|c|}{ Indeks } \\
\cline { 2 - 4 } & & $\mathbf{2 0 1 6}$ & $\mathbf{2 0 1 7}$ \\
\hline 1 & Bank Mandiri & $94,06 \%$ & $92,19 \%$ \\
\hline 2 & Bank BTPN & - & $87,81 \%$ \\
\hline 3 & Bank BCA & $87,16 \%$ & $83,59 \%$ \\
\hline $\mathbf{4}$ & Bank BRI & $\mathbf{8 5 , 1 1 \%}$ & $\mathbf{8 1 , 4 9 \%}$ \\
\hline 5 & Bank Permata & $89,93 \%$ & $81,08 \%$ \\
\hline 6 & Bank BNI & $82,61 \%$ & $80,56 \%$ \\
\hline 7 & Bank CIMB NIAGA & $81,46 \%$ & $78,70 \%$ \\
\hline 8 & Bank Mega & $73,35 \%$ & $78,61 \%$ \\
\hline 9 & Bank Commonwealth & $81,74 \%$ & $76,94 \%$ \\
\hline 10 & Bank Artha Graha & $81,45 \%$ & $75,61 \%$ \\
\hline
\end{tabular}

Sumber: Infobank, 2017

Berdasarkan hasil survei yang dilakukan MRI pada tahun 2016-2017 posisi Bank BRI diketahui belum mampu menjadi Bank yang meraih peringkat pertama untuk penghargaan Best 
Bank Service Excellence kategori performa terbaik layanan internet banking. Peringkat ke 4 (empat) yang diraih oleh Bank BRI belum dapat menunjukkan posisi yang unggul terhadap bank lain seperti Bank Mandiri yang unggul di peringkat pertama, Bank BTPN di peringkat kedua, dan Bank BCA di peringkat ketiga. Indeks presentase dari tahun 2016-2017 Bank BRI juga mengalami penurunan yaitu dari $85,11 \%$ menjadi $81,49 \%$.

\section{Rumusan Masalah}

Berdasarkan latar belakang di atas maka masalah pada Bank BRI adalah tingkat kepuasan nasabah BRI yang masih rendah atas kualitas layanan internet banking, sehingga permasalahan yang diangkat yaitu Bagaimana cara meningkatkan kepuasan nasabah atas kualitas layanan internet banking pada PT Bank Rakyat Indonesia (Persero) Tbk. Unit Banyumanik Semarang.

\section{KAJIAN TEORI}

\section{Pengertian Bank}

Menurut Kasmir (2004:23) bank dikenal sebagai lembaga keuangan yang kegiatan utamanya menerima simpanan giro, tabungan dan deposito. Kemudian bank juga dikenal sebagai tempat untuk meminjam uang (kredit) bagi masyarakat yang membutuhkannya.

Menurut Undang-Undang RI nomor 10 tahun 1998 tanggal 10 November 1998 tentang perbankan, yang dimaksud dengan bank adalah badan usaha yang menghimpun dana dari masyarakat dalam bentuk simpanan dan menyalurkannya kepada masyarakat dalam bentuk kredit dan atau bentuk-bentuk lainnya dalam rangka meningkatkan taraf hidup rakyat banyak.

\section{Kepuasan Nasabah}

Kata kepuasan (satisfaction) berasal dari bahasa latin satis yang berarti cukup baik, memadai dan facio berarti melakukan atau membuat. Kepuasan bisa diartikan sebagai upaya pemenuhan sesuatu (Tjiptono, 2004:146).

Menurut Sulistyorini (2006:74-75) kepuasan adalah bentuk perasaan yang diperoleh pelanggan setelah harapan dan kinerja nyata suatu produk. Ketidakpuasan maupun kepuasan benar-benar bergantung pada penilaian pelanggan berdasarkan perbandingan antara harapan dan kinerja yang dilakukannya.

\section{Kualitas Pelayanan}

Menurut Lupiyoadi (2008:73) kualitas merupakan sebuah kata yang bagi penyedia jasa merupakan suatu yang harus dikerjakan dengan baik. Aplikasi kualitas sebagai sifat dan 
penampilan produk atau kinerja yang merupakan bagian utama strategi perusahaan dalam rangka meraih keunggulan yang berkesinambungan, baik sebagai pemimpin pasar ataupun sebagai strategi untuk terus tumbuh. Jadi, kualitas adalah perpaduan antara sifat dan karakteristik yang menentukan sejauh mana keluaran dapat memenuhi persyaratan kebutuhan nasabah.

Zeithaml \& Bitner dalam Yusnaini (2010) mengungkapkan lima dimensi pokok kualitas pelayanan suatu perusahaan jasa, yaitu:

1. Tangible (bukti fisik)

Yaitu didefinisikan sebagai kehadiran fasilitas fisik, perlengkapan karyawan dan sarana komunikasi. Semua ini merupakan citra dari pelayanan yang akan digunakan oleh konsumen, terutama konsumen baru, untuk mengevaluasi kualitas jasa.

2. Reliability (kehandalan)

Yaitu didefinisikan sebagai kemampuan untuk memenuhi pelayanan yang dijanjikan secara mandiri dan akurat. Dalam pengertian yang luas, reliability berarti bahwa perusahaan memenuhi janjinya, janji pengiriman, penyediaan jasa dan harga.

3. Responsiveness (daya tanggap)

Yaitu kemauan untuk membantu pelanggan dan menyediakan pelayanan yang tibatiba. Dimensi ini menekankan pada perhatian dan respon dalam menangani permintaan konsumen, pertanyaan, keluhan dan masalah. Daya tanggap dikomunikasikan kepada konsumen melalui lamanya mereka harus menunggu untuk dibantu, jawaban atas pertanyaan, atau perhatian terhadap masalah.

4. Assurance (jaminan)

Yaitu pengetahuan karyawan dan kesopanan, kemampuan perusahaan dan karyawan untuk dapat dipercaya dan diyakini oleh pelanngan. Dimensi ini penting untuk jasa-jasa konsumen yang memiliki rasa tidak pasti seperti perbankan, asuransi, broker, kesehatan dan jasa hukum.

\section{Emphaty (empati)}

Yaitu kepedulian, perhatian pribadi yang diberikan kepada konsumen. Konsumen ingin dimengerti dan merasa penting bagi perusahaan. Karyawan pada perusahaan jasa kecil sering kali mengenal nama konsumennya dan membangun hubungan yang merefleksikan pengetahuan mereka tentang kebutuhan dan preferensi konsumen. 


\section{Definisi Internet Banking}

Internet banking merupakan pelayanan jasa bank yang memungkinkan nasabah untuk memperoleh informasi, melakukan komunikasi-komunikasi dan melakukan transaksi perbankan melalui jaringan internet, dan bukan merupakan bank yang hanya menyelenggarakan layanan perbankan melalui internet (Bank Indonesia, 2004).

Menurut Herington \& Weaven (2007) dalam Yusnaini (2010), internet banking adalah bentuk e-layanan di mana pelanggan dapat belajar langsung antara elektronik dan layanan pelanggan dan hal ini secara signifikan dipengaruhi oleh kinerja pelanggan. Secara umum transaksi ini meliputi pengecekan rekening, mengamati daftar transaksi yang menggunakan rekening, dan mentransfer dana dari suatu rekening online ke rekening yang lain.

\section{Penelitian Terdahulu}

Menurut penelitian yang dilakukan oleh Imawan (2009), Ashiva (2015), Akmalia (2016) dan Harmelina (2016) yang menyatakan bahwa kepuasan atas kualitas layanan dapat diukur melalui tangibles, reliability, responsiveness, assurance, dan emphaty.

\section{Kerangka Pemikiran Teoritis}

Berdasarkan uraian teoritis di atas dibangun suatu model kerangka piker teoritis penelitian sebagai berikut:

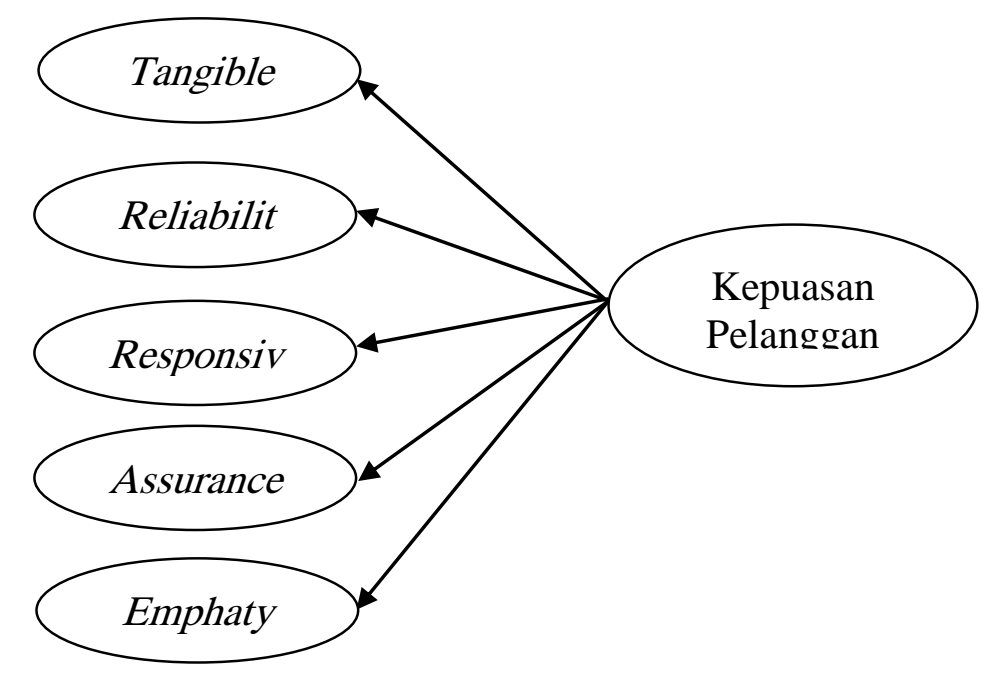

Gambar 1

Kerangka Pikir Teoritis

(sumber : Imawan (2009), Ashiva (2015), Akmalia (2016) dan Harmelina (2016)) 


\section{METODE}

\section{Populasi dan Sampel}

Dalam penelitian ini target populasi adalah seluruh nasabah tabungan BritAma yang menggunakan layanan internet banking pada PT Bank Rakyat Indonesia (Persero) Tbk. Unit Banyumanik Semarang sebanyak 3278 nasabah, sedangkan untuk pengambilan sampel adalah nasabah tabungan BritAma yang menggunakan layanan internet banking.

\section{Prosedur Pengumpulan dan Jenis Data}

Responden yang dituju dalam penelitian ini adalah seluruh nasabah tabungan BritAma yang menggunakan layanan internet banking pada PT Bank Rakyat Indonesia (Persero) Tbk. Unit Banyumanik Semarang. Kemudian responden tersebut dimintai untuk membantu pengisian kuesioner penelitian yang telah disediakan oleh peneliti terkait dengan kepuasan nasabah atas kualitas layanan internet banking.

Jenis data dalam penelitian ini adalah data primer yang diperoleh dari jawaban responden atas kuesioner yang diberikan mengenai kepuasan nasabah atas kualitas layanan internet banking PT Bank Rakyat Indonesia (Persero) Tbk. Unit Banyumanik Semarang.

\section{HASIL DAN PEMBAHASAN}

\section{Uji Validitas dan Uji Reliabilitas}

Uji validitas digunakan untuk mengukur sah atau valid atau tidak suatu kuesioner. Suatu kuesioner dikatakan valid jika pertanyaan pada kuesioner mampu untuk mengungkapkan sesuatu yang akan diukur oleh kuesioner tersebut (Ghozali, 2006:49).

Reliabilitas adalah alat untuk mengukur suatu kuesioner yang merupakan indikator dari suatu variabel atau konstruk. Suatu kuesioner dikatakan reliabel atau handal jika jawaban seseorang terhadap pertanyaan adalah konsisten atau stabil dari waktu ke waktu (Ghozali, 2006:45).

\section{Uji Indeks Kepuasan}

Untuk mengukur tingkat kepuasan nasabah berdasarkan pada atribut-atribut yang berpengaruh digunakan indeks kepuasan dimana perhitungan yang digunakan adalah data mengenai tanggapan dari kualitas layanan berdasarkan kinerja dan tingkat kepentingan masingmasing indikator.

Berdasarkan hasil uji indeks kepuasan disimpulkan bahwa secara keseluruhan nasabah tabungan BritAma yang menggunakan layanan internet banking pada PT Bank Rakyat Indonesia 
(Persero) Tbk. Unit Banyumanik Semarang merasa puas terhadap kinerja yang diberikan, ditunjukkan dengan hasil uji indeks kepuasan yang mendapatkan nilai sebesar 4,046 yang artinya secara keseluruhan responden sudah puas atau sudah memenuhi harapan responden akan indikatorindikator kualitas layanan internet banking yang diberikan PT Bank Rakyat Indonesia (Persero) Tbk. Unit Banyumanik Semarang kepada responden.

\section{Uji Gap Kepuasan}

Dari hasil uji kepuasan dengan menggunakan uji gap kepuasan dapat diketahui bahwa terdapat nasabah BritAma pengguna layanan internet banking Bank BRI Unit Banyumanik Semarang yang merasa tidak puas dengan pelayanan yang diberikan oleh Bank BRI Unit Banyumanik Semarang yaitu nilai sub indikator $\mathrm{X}_{2.4}$ reliability (proses transaksi internet banking jarang terjadi eror) sebesar -0,02, nilai sub indikator $X_{3.1}$ responsiveness (tanggap dalam menangani keluhan nasabah internet banking) sebesar -0,05 dan nilai sub indikator $\mathrm{X}_{3.2}$ responsiveness (adanya langkah dalam menyelesaikan kesalahan transaksi internet banking) sebesar $-0,05$.

\section{Cara Meningkatkan Kepuasan Nasabah}

Berdasarkan beberapa uraian dan analisis yang telah dibahas pada bab-bab sebelumnya, berkenaan dengan penelitian yang berjudul "Analisis Tingkat Kepuasan Nasabah Atas Kualitas Layanan Internet Banking pada PT Bank Rakyat Indonesia (Persero) Tbk. Unit Banyumanik Semarang”, maka cara untuk meningkatkan kepuasan nasabah adalah sebagai berikut:

\section{Tabel 2}

\section{Cara meningkatkan Kepuasan Nsabah}

\begin{tabular}{|c|c|c|c|c|}
\hline NO & Indikator & $\begin{array}{c}\text { Hasil Uji } \\
\text { Gap }\end{array}$ & Ket. & Cara Meningkatkan Kepuasan Nasabah \\
\hline 1. & $\begin{array}{lr}\text { Website } & \text { internet } \\
\text { banking dilengkapi } \\
\text { dengan } & \text { layanan } \\
\text { informasi } & \text { internet } \\
\text { banking } & \end{array}$ & 0,02 & Puas & $\begin{array}{l}\text { Mempertahankan dan meningkatkan kepuasan } \\
\text { nasabah dari sisi layanan informasi internet banking } \\
\text { yang lengkap. }\end{array}$ \\
\hline 2. & $\begin{array}{l}\text { Website internet } \\
\text { banking } \\
\text { diakses }\end{array}$ & 0,01 & Puas & $\begin{array}{l}\text { Mempertahankan dan meningkatkan kepuasan } \\
\text { nasabah dari sisi layanan internet banking yang } \\
\text { mudah diakses. }\end{array}$ \\
\hline 3. & $\begin{array}{lr}\text { Website } & \text { internet } \\
\text { banking } & \text { memiliki } \\
\text { tampilan } & \text { yang } \\
\text { menarik } & \end{array}$ & 0,01 & Puas & $\begin{array}{l}\text { Mempertahankan dan meningkatkan kepuasan } \\
\text { nasabah dari sisi website internet banking memiliki } \\
\text { tampilan yang menarik. }\end{array}$ \\
\hline
\end{tabular}




\begin{tabular}{|c|c|c|c|c|}
\hline 4. & $\begin{array}{l}\text { Website internet } \\
\text { banking } \\
\text { menyediakan iklan } \\
\text { dan fitur-fitur yang } \\
\text { jelas }\end{array}$ & 0,01 & Puas & $\begin{array}{l}\text { Mempertahankan dan meningkatkan kepuasan } \\
\text { nasabah dari sisi tersedianya iklan dan fitur-fitur } \\
\text { yang jelas. }\end{array}$ \\
\hline 5. & $\begin{array}{l}\text { Keakuratan } \\
\text { informasi website } \\
\text { internet banking }\end{array}$ & 0,01 & Puas & $\begin{array}{l}\text { Mempertahankan dan meningkatkan kepuasan } \\
\text { nasabah dari sisi keakuratan informasi website } \\
\text { internet banking. }\end{array}$ \\
\hline 6. & $\begin{array}{l}\text { Ketepatan } \text { waktu } \\
\text { dalam transaksi } \\
\text { internet banking }\end{array}$ & 0,01 & Puas & $\begin{array}{l}\text { Mempertahankan dan meningkatkan kepuasan } \\
\text { nasabah dari sisi layanan internet bankingyang } \\
\text { ditawarkan dapat dipercaya. }\end{array}$ \\
\hline 7. & $\begin{array}{l}\text { Kemudahan } \\
\text { menghubungi call } \\
\text { centre }\end{array}$ & 0,01 & Puas & $\begin{array}{l}\text { Mempertahankan dan meningkatkan kepuasan } \\
\text { nasabah dengan memberikan kemudahan dalam } \\
\text { menghubungi call centre. }\end{array}$ \\
\hline 8. & $\begin{array}{l}\text { Proses transaksi } \\
\text { internet banking } \\
\text { jarang terjadi eror }\end{array}$ & $-0,02$ & $\begin{array}{l}\text { Tidak } \\
\text { Puas }\end{array}$ & $\begin{array}{l}\text { Memperbaharui sistem secara berkala agar tidak } \\
\text { terjadi kendala atau eror saat nasabah melakukan } \\
\text { proses transaksi internet banking. }\end{array}$ \\
\hline 9. & $\begin{array}{l}\text { Tanggap dalam } \\
\text { menanggapi } \\
\text { keluhan nasabah }\end{array}$ & $-0,05$ & $\begin{array}{l}\text { Tidak } \\
\text { Puas }\end{array}$ & $\begin{array}{l}\text { Memberikan ketanggapan secara cepat dan tepat } \\
\text { terhadap keluhan nasabah. Serta mendengarkan } \\
\text { keluhan nasabah secara seksama. }\end{array}$ \\
\hline 10. & $\begin{array}{l}\text { Adanya langkah } \\
\text { dalam menyelesaikan } \\
\text { kesalahan transaksi } \\
\text { internet banking }\end{array}$ & $-0,05$ & $\begin{array}{l}\text { Tidak } \\
\text { Puas }\end{array}$ & $\begin{array}{l}\text { Melakukan tindakan secara cepat dan tepat dalam } \\
\text { menyelesaikan kesalahan transaksi internet banking. }\end{array}$ \\
\hline 11. & $\begin{array}{l}\text { Prosedur layanan } \\
\text { call centre jelas }\end{array}$ & 0,01 & Puas & $\begin{array}{l}\text { Mempertahankan dan meningkatkan kepuasan } \\
\text { nasabah dari sisi prosedur layanan call centre yang } \\
\text { jelas. }\end{array}$ \\
\hline 12. & $\begin{array}{l}\text { Jaminan jika terjadi } \\
\text { kesalahan transaksi } \\
\text { internet banking }\end{array}$ & 0,01 & Puas & $\begin{array}{l}\text { Mempertahankan dan meningkatkan kepuasan } \\
\text { nasabah dengan memberikan jaminan bila terjadi } \\
\text { kesalahan transaksi internet banking. }\end{array}$ \\
\hline 13. & $\begin{array}{l}\text { Jaminan keamanan } \\
\text { untuk transaksi } \\
\text { internet banking }\end{array}$ & 0,01 & Puas & $\begin{array}{l}\text { Mempertahankan dan meningkatkan kepuasan } \\
\text { nasabah dengan memberikan jaminan keamanan } \\
\text { untuk transaksi internet banking. }\end{array}$ \\
\hline 14. & $\begin{array}{l}\text { Jaminan password } \\
\text { internet banking } \\
\text { yang tidak mudah } \\
\text { terlacak }\end{array}$ & 0,01 & Puas & $\begin{array}{l}\text { Mempertahankan dan meningkatkan kepuasan } \\
\text { nasabah dengan memberikan jaminan password } \\
\text { internet banking yang tidak mudah terlacak. }\end{array}$ \\
\hline 15. & $\begin{array}{l}\text { Ada layanan call } \\
\text { centre yang } \\
\text { melayani } 24 \text { jam }\end{array}$ & 0,02 & Puas & $\begin{array}{l}\text { Mempertahankan dan meningkatkan kepuasan } \\
\text { nasabah dengan memberikan layanan call centre } \\
\text { yang melayani } 24 \text { jam. }\end{array}$ \\
\hline 16. & $\begin{array}{ll}\text { Ada menu help di } \\
\text { website internet } \\
\text { banking }\end{array}$ & 0,04 & Puas & $\begin{array}{l}\text { Mempertahankan dan meningkatkan kepuasan } \\
\text { nasabah dari sisi adanya menu help di website } \\
\text { internet banking. }\end{array}$ \\
\hline 17. & $\begin{array}{l}\text { Ada kotak saran di } \\
\text { website internet } \\
\text { banking }\end{array}$ & 0,02 & Puas & $\begin{array}{l}\text { Mempertahankan dan meningkatkan kepuasan } \\
\text { nasabah dari sisi adanya kotak saran dalam website } \\
\text { internet banking. }\end{array}$ \\
\hline
\end{tabular}




\begin{tabular}{|l|l|l|l|l|}
18. & $\begin{array}{l}\text { Tersedia fasilitas } \\
\text { internet banking } \\
\text { yang lengkap }\end{array}$ & 0,01 & Puas & $\begin{array}{l}\text { Mempertahankan dan meningkatkan kepuasan } \\
\text { nasabah dengan menyediakan fasilitas internet } \\
\text { banking yang lengkap. }\end{array}$ \\
\hline
\end{tabular}

Sumber: Data yang diolah (2019)

\section{PENUTUP}

\section{Kesimpulan}

Berdasarkan beberapa uraian dan analisis yang telah dibahas pada bab - bab sebelumnya, maka berkenaan dengan penelitian yang berjudul "Analisis Tingkat Kepuasan Nasabah Atas Kualitas Layanan Internet Banking pada PT Bank Rakyat Indonesia (Persero) Tbk. Unit Banyumanik Semarang", dengan menggunakan metode analisis indeks kepuasan nasabah dan analisis gap kepuasan, dapat disimpulkan bahwa:

1. Berdasarkan metode analisis data yaitu uji validitas, dapat disimpulkan bahwa semua indikator pertanyaan tentang kinerja dan harapan atas kualitas layanan internet banking pada PT Bank Rakyat Indonesia (Persero) Tbk. Unit Banyumanik Semarang, yang meliputi dimensi tangible (bukti fisik), reliability (kehandalan), responsiveness (daya tanggap), assurance (jaminan), dan emphaty (empati) dinyatakan valid yaitu 0,000.

2. Berdasarkan metode analisis data yaitu uji reliabilitas, dapat disimpulkan bahwa semua indikator pertanyaan tentang kinerja dan harapan atas kualitas layanan internet banking pada PT Bank Rakyat Indonesia (Persero) Tbk. Unit Banyumanik Semarang, yang meliputi dimensi tangible (bukti fisik), reliability (kehandalan), responsiveness (daya tanggap), assurance (jaminan), dan emphaty (empati) dinyatakan reliabel karena angka yang diperoleh dari tiap-tiap pertanyaan semua indikator memiliki Cronbach's Alpha diatas 0,60.

3. Dari hasil uji kepuasan dengan menggunkan uji satisfaction indeks atau indeks kepuasan dapat diketahui bahwa nasabah BritAma pengguna layanan internet banking Bank BRI Unit Semarang merasa puas dengan pelayanan yang diberikan oleh Bank BRI Unit Banyumanik Semarang karena memperoleh nilai indeks kepuasan/weighting average sebesar 4,046 yang berada diantara jenjang skala 3,43 - 4,23 yang berarti puas.

4. Dari hasil uji kepuasan dengan menggunakan uji gap kepuasan dapat diketahui bahwa terdapat nasabah BritAma pengguna layanan internet banking Bank BRI Unit Banyumanik Semarang yang merasa tidak puas dengan pelayanan yang diberikan oleh Bank BRI Unit 
Banyumanik Semarang yaitu nilai sub indikator $\mathrm{X}_{2.4}$ reliability (proses transaksi internet banking jarang terjadi eror) sebesar -0,02, nilai sub indikator $\mathrm{X}_{3.1}$ responsiveness (tanggap dalam menangani keluhan nasabah internet banking) sebesar -0,05 dan nilai sub indikator $\mathrm{X}_{3.2}$ responsiveness (adanya langkah dalam menyelesaikan kesalahan transaksi internet banking) sebesar -0,05. Maka dari itu sub indikator yang tidak puas tersebut harus mendapatkan perhatian khusus dari Bank BRI Unit Banyumanik Semarang.

5. Berdasarkan analisis hasil uji indeks kepuasan nasabah dan hasil uji gap kepuasan nasabah yang telah dibahas, berkenaan dengan penelitian yang berjudul "Analisis Tingkat Kepuasan Nasabah Atas Kualitas Layanan Internet Banking pada PT Bank Rakyat Indonesia (Persero) Tbk. Unit Banyumanik Semarang”, dapat disimpulkan bahwa cara untuk meningkatkan kepuasan nasabah, sebagai berikut:

a. Memperbaharui sistem secara berkala agar tidak terjadi kendala atau eror saat nasabah melakukan proses transaksi internet banking.

b. Memberikan ketanggapan secara cepat dan tepat terhadap keluhan nasabah internet banking. Serta mendengarkan keluhan nasabah secara seksama.

c. Melakukan tindakan secara cepat dan tepat dalam menyelesaikan kesalahan internet banking.

\section{Keterbatasan Penelitian}

Keterbatasan dalam penelitian ini adalah dalam melakukan proses pengisian kuesioner, tidak semua nasabah bersedia mengisi semua pertanyaan yang diberikan karena terbatasnya waktu yang dimiliki para responden. Keterbatasan penelitian selanjutnya adalah literatur yang dimiliki oleh peneliti kurang begitu lengkap sehingga terjadi banyak kekurangan karena terbatasnya waktu dan biaya yang dimiliki peneliti.

\section{Agenda Penelitian Mendatang}

Untuk agenda penelitian mendatang sebaiknya disarankan untuk menambah jumlah responden dan memperbanyak pertanyaan dalam kuesioner sehingga hasil penelitian yang diperoleh mampu menggambarkan keadaan sesungguhnya dari objek penelitian dan bagi penelitian selanjutnya diharapkan dapat menambahkan sub indikator adanya program untuk pengguna internet banking menurut hasil penelitian Yusnaini (2011) dan website internet banking menyediakan bahasa yang mudah untuk dimengerti menurut hasil penelitian Kurniasari (2016). 


\section{DAFTAR PUSTAKA}

Akmalia, Ifki. 2015. “Analisis Kepuasan Nasabah Atas Dimensi Kualitas Pelayanan Bank Syariah Mandiri Malang”.Jurnal Manajemen Bisnis.

Ashiva, DitaLaila. 2015. “Analisis Tingkat KepuasanNasabah Tabungan Simpedes Atas Kualitas Pelayanan PT. Bank Rakyat Indonesia (Persero), Tbk Unit Ngesrep Semarang”.Journal Of Social And Politic, Business Administration.

Harmelina.2015. "Analisis Tingkat Kepuasan Nasabah Atas Pelayanan PadaPT. Bank Negara Indonesia (Persero), Tbk Cabang Pekanbaru”.Jurnal Manajemen dan Bisnis.

Imawan, Zera. 2009. “Analisa Kepuasan Pelanggan Atas Kualitas Pelayanan Jasa Pada Pemegang Kartu Kredit Everyday Bank Mandiri Di Jakarta".Journal of Business Strategy and Execution.Vol. 1 No.2 June 2009.

Kurniasari, Tertanda Puspita. 2016. "Pengaruh Kualitas Layanan Terhadap Kepuasan Nasabah Internet Banking Bank BRI Surabaya”. Skripsi. Surabaya: Jurusan Manajemen Sekolah Tinggi Ilmu Ekonomi.

Susetyorini. 2012. "Pengaruh Kualitas Layanan Nasabah Online Terhadap Kualitas Layanan Internet Banking Secara Keseluruhan Dan Terhadap Kepuasan Nasabah Bank Di Surabaya”. Jurnal Manajemen dan Bisnis.

Wahyuni, Sri. 2012. “Analisis Pengaruh Kualitas Layanan Internet Banking dan Tingkat Kepuasan Nasabah pada PT. Bank Rakyat Indonesia (Persero) Tbk Kantor Cabang Pembantu Jamsostek Jakarta”. Jurnal Manajemen dan Bisnis.Vol. 19, No.17.

Yusnaini. 2010. "Pengaruh Kualitas Pelayanan Internet Banking Terhadap Kepuasan dan Loyalitas Konsumen Pada Bank Swasta”. Jurnal Dinamika Akuntansi. Vol. 12, No.1.

Arsyad, Soeratno. 1995. Metodologi Penelitian Untuk Ekonomi dan Bisnis.Yogyakarta : UPPAMP YKPN.

Bank Indonesia. 1998. Undang-Undang Republik Indonesia No.10 Tahun 1998 Tentang Perbankan. http://www.bi.go.id.

Ghozali, Imam. 2006. Aplikasi Analisis Multivariate dengan Program SPSS. Semarang :Badan Penerbit Universitas Diponegoro.

Hasibuhan, Malayu S.P. 2008. Manajemen Sumberdaya Manusia, Edisi Revisi.Jakarta :Bumi Aksara. 
Jogiyanto. 2018. Metodologi Penelitian Bisnis. Yogyakarta :BPFE Yogyakarta.

Kasmir. 2004. Bank dan Lembaga Keuangan Lainnya. Jakarta : PT. Raja Grafindo Persada.

Kasmir. 2012. Manajemen Perbankan. Jakarta : PT. Raja Grafindo Persada.

Kotler, Philip. 2008. Manajemen Pemasaran, Edisi Milenium 1. Jakarta : PT Prenhallindo.

Lupiyoadi, Rambat. 2001. Manajemen Pemasaran Jasa Teori danPraktik. Jakarta : PT. Salemba Emban Patria.

Lupiyoadi, Rambat. 2013. Manajemen Pemasaran Jasa Berbasis Kompetensi (Edisi 3). Jakarta :Salemba Empat

Lupiyoadi dan A Hamdani. 2008. Manajemen Pemasaran Jasa, Edisi 2. Jakarta :Salemba Empat.

Majalah Infobank. Mei 2017. The Best Bank Service Excellent 2017.

Margono. 2010. Metodologi Penelitian Pendidikan. Jakarta : PT. Rineka Cipta.

Marzuki. 2000. Metodologi Riset.Yogyakarta : PT. Prasetya Widia Pratama.

Simamora, Bilson. 2004. Riset Pemasaran. Jakarta :Gramedia Pustaka Utama.

Sugiyono. 2013. Metode Penelitian Kuantitatif Kualitatif dan R\&D. Bandung: Alfabeta.

Sulistyorini, Utami Tri. 2006. Strategi Pemasaran Jasa Pada Lembaga Keuangan. Semarang :Penerbit Polines.

Tjiptono, Fandy. 2004. Manajemen Jasa. Yogyakarta: ANDI.

Umar, Huesein. 2003. Metode Riset Akuntansi Terapan. Jakarta: Ghalia Indonesia.

Umar, Husein. 2003. Metode Riset Perilaku KonsumenJasa. Jakarta :Ghalia Indonesia.

Tim Penyusunan Pedoman Tugas Akhir. 2014. Pedoman Penyusunan Tugas Akhir Jurusan Akuntansi Politeknik Negeri Semarang. Semarang : PoliteknikNegeri Semarang. 